(2) Open Access Full Text Article

REVIEW

\title{
Immunotherapy of melanoma with the immune costimulatory monoclonal antibodies targeting CDI37
}

This article was published in the following Dove Press journal:

Clinical Pharmacology:Advances and Applications

30 August 2013

Number of times this article has been viewed

\author{
Shi-Yan Li \\ Yizhen Liu \\ Cancer Research Institute, Scott \\ and White Healthcare, Temple, \\ TX, USA
}

Correspondence: Shi-Yan Li

Cancer Research Institute, Scott and White Healthcare, 570I South Airport

Road, Temple, TX 76502, USA

Tel +I 254724 I595

Email sli@sw.org

\begin{abstract}
Knowledge of how the immune system recognizes and attempts to control cancer growth and development has improved dramatically. The advent of immunotherapies for cancer has resulted in robust clinical responses and confirmed that the immune system can significantly inhibit tumor progression. Until recently, metastatic melanoma was a disease with limited treatment options and a poor prognosis. CD137 (also known as 4-1BB) a member of the tumor necrosis factor (TNF) receptor superfamily, is an activation-induced T cell costimulator molecule. Growing evidence indicates that anti-CD137 monoclonal antibodies possess strong antitumor properties, the result of their powerful capability to activate CD8+ T cells, to produce interferon (IFN)- $\gamma$, and to induce cytolytic markers. Combination therapy of anti-CD137 with other anticancer agents, such as radiation, has robust tumor-regressing abilities against nonimmunogenic or poorly immunogenic tumors. Of importance, targeting CD137 eliminates established tumors, and the fact that anti-CD137 therapy acts in concert with other anticancer agents and/or radiation therapy to eradicate nonimmunogenic and weakly immunogenic tumors is an additional benefit. Currently, BMS-663513, a humanized anti-CD137 antibody, is in clinical trials in patients with solid tumors, including melanoma, renal carcinoma, ovarian cancer, and B-cell malignancies. In this review, we discuss the basis of the therapeutic potential of targeting CD137 in cancer treatment, focusing in particular, on BMS-663513 as an immune costimulatory monoclonal antibody for melanoma immunotherapy.
\end{abstract}

Keywords: anti-CD137 monoclonal antibodies, immune costimulator molecule, BMS663513

\section{Introduction}

Melanoma is a malignant tumor of the melanocytes that leads to 48,000 deaths annually worldwide. ${ }^{1}$ Melanoma is less common than other skin cancers; however, it is much more dangerous if it is not found early. It is the most common cancer in young adults aged 20 to 30 years old and the leading cause of cancer death in women aged 25 to 30 years old. Although the mortality rates of early stage melanoma are generally low, stage IV metastatic disease predicts poor disease outcome, with less than $10 \%$ survival rate at 5 years from diagnosis. ${ }^{2}$

Depending on the stage of the disease, treatments for melanoma include surgical removal of the tumor and draining of lymph nodes as well as the amputation of affected body parts. If melanoma is found early, while it is still small and thin, and if it is completely removed, then the chance of cure is high. The likelihood of the melanoma coming back or spreading depends on how deeply it has extended into the layers of the skin. For melanomas that come back or spread, treatments include 
chemo- and immunotherapy or radiation therapy. Chemotherapy and radiation therapy are generally not as effective in melanoma as in other types of cancer. In contrast, treatments targeted at improving immunity, such as high dose interleukin (IL)-2, anti-cytotoxic T-lymphocyte-associated antigen-4 (anti-CTLA-4) antibodies, and interferon (IFN)- $\alpha$ are efficacious, at least in selected subsets of melanoma patients, indicating a prominent role for the immune system in the control of melanoma. ${ }^{3-5}$

The rationale of immunotherapy for melanoma stemmed from the fact that sampling and the study of lymphocytes infiltrating tumors was facilitated by their relatively high percentage in melanoma compared with other cancers, suggesting the existence of a local antitumor immune response. ${ }^{6}$ These tumor-infiltrating lymphocytes (TILs) were expanded in culture with recombinant IL-2 and displayed cytolytic activity against autologous melanoma cells in vitro. ${ }^{7}$ The presence of CD4+ and CD8+ T cells among the TILs was found to positively correlate with favorable disease outcome, further demonstrating an important role for T cells in antitumor immunity. ${ }^{5}$ Since these findings, a broad spectrum of immunotherapies has been developed to boost protective $T$ cell responses against melanoma (eg, high-dose IL-2 and type I IFN) or to unleash endogenous responses to tumor cells (eg, anti-CTLA-4 and anti-Programmed death 1 (PD-1) monoclonal antibodies). ${ }^{8,9}$

\section{Immunotherapy of melanoma}

Cancer immunotherapy uses the immune system to reject cancer. The main mechanism is the stimulation of the patient's immune system to attack the malignant tumor cells that are responsible for the disease. This can be accomplished either through immunization of the patient (eg, by administering a cancer vaccine, such as Dendreon's Provenge ${ }^{\circledR}[$ Dendreon Corp, Seattle, WA, USA]), in which case the patient's own immune system is trained to recognize tumor cells as targets to be destroyed, or through the administration of therapeutic antibodies, in which case the patient's immune system can be modulated through the administration of therapeutic antibodies, such as anti-CD137. ${ }^{10-12}$

Over the years, many immunotherapeutic approaches have been investigated in patients with melanoma, with varying clinical success. Generally, the immunotherapeutic approaches used in the treatment of melanoma may fall into the categories of specific or nonspecific therapies (Table 1). Specific therapies use defined antigen sources; whereas in nonspecific therapies, the antigen source is defined by the host. ${ }^{5,6}$ Cytokines, for example, are nonspecific, active agents that induce $\mathrm{T}$ cell activation and proliferation. High-dose IL-2
Table I Immunotherapeutic strategies in clinical development

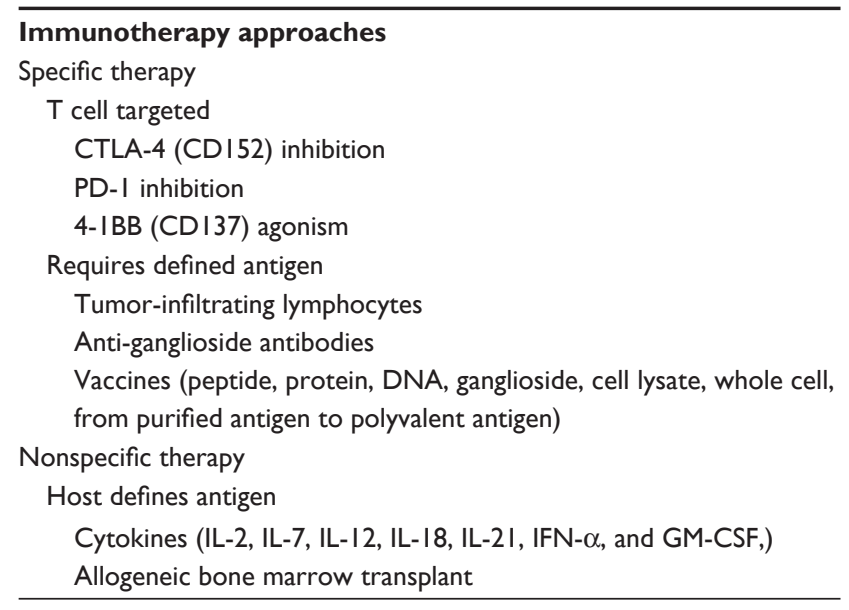

Abbreviations: CTLA-4, cytotoxic T-lymphocyte-associated antigen-4; DNA, deoxyribonucleic acid; GM-CSF, granulocyte-macrophage colony-stimulating factor; IFN- $\alpha$, interferon alpha; IL, interleukin; PD-I, programmed death I.

has been shown to induce durable responses in a minority of patients with metastatic melanoma and was approved by the Food and Drug Administration for the treatment of patients with this disease in $1998 .^{7}$ Adoptive cell therapy with TILs is an example of a specific adoptive approach to therapy that has proven to be an effective treatment of metastatic melanoma patients. Adoptive cell therapy involves the identification and ex vivo growth of antitumor lymphocytes, which are then infused into the cancer patient. ${ }^{5}$ Adoptive cell therapy has been shown to result in the durable complete regression of bulky metastatic melanoma in patients who were refractory to approved treatments. ${ }^{4}$ Despite promising clinical results, however, the extensive effort, cost, and time required to generate individual TIL cultures limit the use of adoptive cell therapy to only a few institutions. ${ }^{3,6,13}$

Another specific active approach of treatment is the use of monoclonal antibodies that target $\mathrm{T}$ cells. Ipilimumab and tremelimumab, for example, are monoclonal antibodies against CTLA-4 that augment $T$ cell activation and proliferation to enhance the immune response against tumors. In two recent Phase III trials, ipilimumab significantly improved overall survival in pretreated and previously untreated patients, with hazard ratios for death of 0.68 for the group receiving ipilimumab plus the synthetic peptide cancer vaccine gp100 compared with the group receiving gp100 alone $(P<0.001)$, of 0.66 for the group of pretreated patients receiving ipilimumab alone compared with those receiving gp100 alone $(P=0.003)$, and of 0.72 for the group of previously untreated patients receiving ipilimumab plus dacarbazine compared with those receiving dacarbazine alone $(P<0.001) .^{3,5,7,13}$ Based on the results in pretreated 
patients in 2011, ipilimumab, at a dose of $3 \mathrm{mg} / \mathrm{kg}$, became the first agent, since IL-2, in 1998, in the United States and fotemustine, in 1989, in selected European countries, to be approved for the treatment of patients with metastatic melanoma. Monoclonal antibodies against PD-1 or its ligand (PD-L1), and CD137 agonists are also in development. ${ }^{3,5,14}$ The PD-1/PD-L1 pathway is a negative regulator of $\mathrm{T}$ cell proliferation and cytokine production; therefore, the blockade of PD-L1/PD-1 increases T cell activation and the elimination of tumor cells. Moreover, several CD137 agonists show great potential for application to immunotherapy for melanoma. ${ }^{14}$ For example, BMS-663513, a fully humanized monoclonal antibody against CD137, has completed Phase I and II trials investigating its anticancer properties in patients with melanoma.

Although immunotherapy holds much promise for the treatment of melanoma, it is important to note that it can be associated with novel mechanism-based toxic effects. Finding a balance between the effectiveness of immunotherapies and the incidence of immune-related adverse events is therefore an important consideration in the field of immunotherapy for melanoma.

\section{Immunotherapy with immune costimulatory anti-CD I 37}

CD137, also known as an inducible T cell surface molecule, is a $30 \mathrm{kDa}$ glycoprotein of the tumor necrosis factor (TNF) receptor superfamily. Its alternative names are TNF receptor superfamily member 9 (TNFRSF9), and 4-1BB, and it is induced by lymphocyte activation. It is mainly expressed on activated CD4+ and CD8+ T cells, activated B cells, and natural killer $(\mathrm{NK})$ cells but can also be found on resting monocytes and dendritic cells. As a costimulatory molecule, CD137 is involved in the activation and survival of CD4+, CD8+, and NK cells. Its engagement with anti-CD137 monoclonal antibody enhances the expansion of T cells and activates them to secrete cytokines. ${ }^{15-17}$ The biological effects of anti-CD137 on CD4+ and CD8+T cells, by targeting CD137, are illustrated in Figure 1.

The best characterized activity of CD137 is its costimulatory activity for activated T cells. Crosslinking of CD137 enhances $\mathrm{T}$ cell proliferation, IL-2 secretion, survival, and cytolytic activity. Further, it can enhance immune activity to eliminate tumors in mice. ${ }^{18-20}$ The importance of the CD137 pathway has been underscored in a number of diseases, including cancer. Growing evidence indicates that anti-CD137 monoclonal antibodies possess strong antitumor properties. $^{20}$

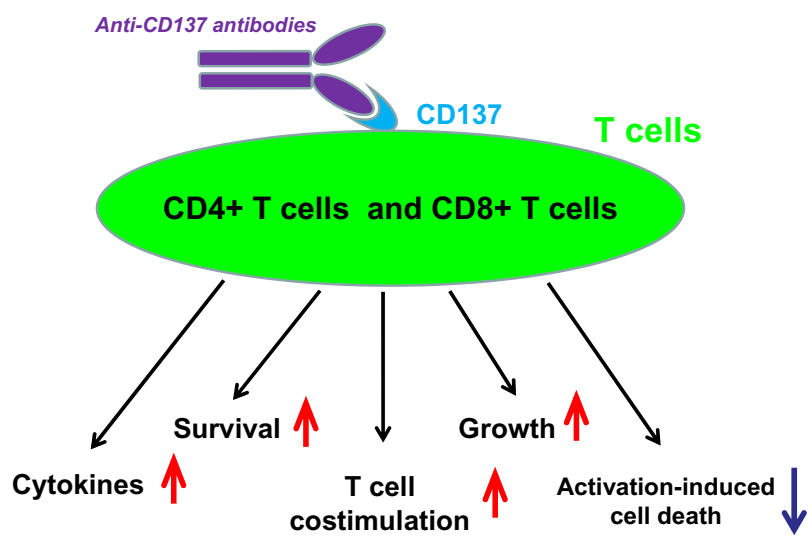

Figure I Biological functions of anti-CD 137 monoclonal antibodies on T cells, by targeting CDI37.

The first comprehensive evidence that anti-CD137 antibodies have strong antitumor effects came to light through studies of the action of monoclonal antibodies against the CD137+ T cell-activation molecule in eradicating established tumors. ${ }^{21}$ Administration, in mice bearing the tumors of poorly immunogenic Ag104A sarcoma and highly tumorigenic P815 mastocytoma, with anti-CD137 was shown to significantly inhibit tumor growth by increasing cytotoxic T lymphocyte activity. ${ }^{21}$ In the years that followed, studies substantiated the antitumor effects of CD137 signaling and extended our understanding of how the CD137 signal suppresses tumor development. The first important observation was that the administration of anti-CD137 caused the loss of humoral activity against $\mathrm{T}$ cell-dependent antigens, indicating that anti-CD137 monoclonal antibodies may effectively suppress $\mathrm{T}$ cell-dependent humoral immunity. ${ }^{22}$ This observation led to the testing of and the realization that anti-CD137 monoclonal antibodies could suppress and reverse the development of autoimmune diseases, such as experimental autoimmune encephalomyelitis, systemic lupus erythematosus, and collagen-induced arthritis. ${ }^{20}$ In addition, the administration of human anti-CD137 monoclonal antibody to suppress human xenografts in severe combined immunodeficient mice was found to result in significant inhibition of tumor growth. ${ }^{23}$ Anti-CD137 treatment of mice that had received MCA205 sarcoma or GL261 glioma cells 3 days previously was shown to prolong survival and cause regression of the tumors. These effects were dependent on T cells, because anti-CD137 failed to suppress tumor growth in mice depleted of CD4+ and/or CD8+ T cells and promoted tumor growth in severe combined immunodeficient mice. ${ }^{24,25}$ When treated with anti-CD137 monoclonal antibody, substantial tumor eradication, delayed tumor progression, and prolonged survival were achieved in $R A G 2-/-$ mice that 
were given P1A-expressing J558 cells and P1A-specific CD8+ T cells. ${ }^{26}$

Treatment of tumor-bearing mice with immune costimulatory anti-CD137 has been found to significantly reduce the tumor burden. Cell-depletion studies ${ }^{27}$ have shown that the antitumor effects of anti-CD137 depend on CD8+ T cells and not on CD4+ T cells or NK cells. Further analysis revealed that this tumor regression was correlated with increased numbers of lymphocytes in the mice spleens and tumordraining lymph nodes, and increased numbers of apoptotic cells and TILs. Furthermore, mice that received this combination therapy rapidly rejected tumors when rechallenged, suggesting that long-lasting tumor antigen-specific memory had been established. ${ }^{27-29}$

Moreover, anti-CD137 was found on endothelial tumor cells, and its expression was upregulated upon activation. ${ }^{29}$ Exposure of tumor endothelial cells to anti-CD137 monoclonal antibodies upregulated intercellular adhesion molecule 1 (ICAM-1), vascular cell adhesion molecule 1 (VCAM-1), and E-selectin. ${ }^{29}$ Upon adoptive transfer into RAG1-/mice and after treatment with immune costimulatory antiCD137 monoclonal antibody, the donor T cells displayed enhanced migration into tumor tissue. ${ }^{29}$ Inhibition studies using anti-ICAM-1 and anti-VCAM-1 antibodies showed that the stimulation of ICAM-1 and VCAM-1 expression on tumor endothelial cells by anti-CD137 was responsible for the enhanced $\mathrm{T}$ cell migration into malignant tissue. ${ }^{29}$ These observations suggest that the in vivo anticancer effects of anti-CD137 monoclonal antibodies encompass both $\mathrm{T}$ and non-T cells. Adoptive $\mathrm{T}$ cell therapy of cancers involves expanding TILs ex vivo in the presence of IL-2 and reinfusing them into tumor-bearing hosts. ${ }^{30}$ One of the challenges facing adoptive $\mathrm{T}$ cell therapy is the activation-induced cell death of the TILs and loss of key accessory molecules due to the ex vivo culture conditions. This can lead to reduced in vivo persistence after adoptive transfer. ${ }^{30}$ Hernandez-Chacon et al observed that ex vivo expansion of TILs resulted in the loss of CD27 and CD28 expression but gain of CD137 expression and, to a lesser extent, CD134/OX40. ${ }^{31}$ The stimulation of these cells with agonistic anti-CD137 monoclonal antibodies significantly inhibited their activation-induced cell death, enhanced their cell division, and increased their cytolytic activity against melanoma cells. ${ }^{31}$ Similarly, stimulation of human CD3+ CD56+ NK cells with anti-CD137 increased their cytolytic activity, as shown by their ability to lyse A549 tumor cells. ${ }^{32}$ Cytokine-induced killer cells, generated in vitro by stimulation with anti-CD3/IL-2/IFN- $\gamma$, are potent anticancer agents. ${ }^{33,34}$ When a group of severe combined immunodeficient mice were engrafted with A549 tumor cells and received, in addition, anti-CD137 and cytokineinduced killer cells, their mortality rate was reduced. ${ }^{32}$ Further analysis revealed the increased expression of IFN- $\gamma$, IL-2, and TNF- $\alpha$, and decreased expression of transforming growth factor (TGF)- $\beta$, IL-4, and IL-10 in CD3+ CD56+ cells taken from the treated mice. ${ }^{32}$ Taken together, these findings underline the important role of CD137 signaling in tumor development and the therapeutic potential of antiCD137 monoclonal antibodies in cancer therapy. ${ }^{35}$

Recently, most studies have focused on two antiCD137 monoclonal antibodies: BMS-469492, which is an anti-murine CD137 monoclonal antibody; and BMS-663513, which is a fully human immunoglobulin (Ig)G4 monoclonal antibody against human CD137. BMS-469492 was used for studies in murine tumor models, and it does not cross-react with BMS-663513. Both are agonistic monoclonal antibodies and do not block the interaction of CD137 with its natural ligand, CD137L. It is of note that monoclonal antibodies that do block CD137L binding show similar functional antitumor activities when compared with nonblocking monoclonal antibodies. BMS-663513 provides a costimulatory signal to human T cells, causing an increase in IFN- $\gamma$ production and increasing their survival. In fact, the functional effects of BMS-663513 were demonstrated on human and monkey $\mathrm{T}$ cells and peripheral blood mononuclear cells (PBMCs), where IFN- $\gamma$ production was enhanced compared with controls. ${ }^{35}$ The effect of BMS469492 was studied along with tumor lysate-pulsed dendritic cells (TP-DCs), in the C57BL/6 (B6) murine melanoma model. BMS-469492 or tumor lysate-pulsed dendritic cells alone had no antitumor activity against 3-day established metastases. However, the combination produced significant tumor regression in which CD8+ and CD4+ T cells and NK cells played a role. ${ }^{36}$ In addition, anti-CD137 monoclonal antibody was synergistic with other immunostimulatory monoclonal antibodies, ${ }^{37,38}$ adoptive $\mathrm{T}$ cell therapy, ${ }^{26}$ and conventional chemo- and radiotherapy. ${ }^{39}$ As mentioned earlier, the most exciting feature of CD137 immune costimulatory therapy is that it provides strong synergistic effects with many types of therapies, at the preclinical level. Among these are chemotherapy, radiotherapy, adoptive $\mathrm{T}$ cell therapy, vaccines, cytokines, and other immunostimulatory monoclonal antibodies. ${ }^{35}$ Furthermore, very recent studies have reported that anti-CD137 monoclonal antibodies $^{29,31}$ induced multifocal mononuclear cell infiltrates in the liver of BALB/c and C57BL/6 mice. These infiltrates were composed primarily of CD8+ T cells having diverse $\mathrm{T}$ cell receptor (TCR) V $\alpha-\beta$ phenotypes. C57BL/6 mice also displayed evidence of dysregulated hematopoiesis in the spleen, 
lymphocyte trafficking, lymphopenia, thrombocytopenia, and anemia, in an anti-CD137 dose-dependent manner. All of these outcomes were T cell - and anti-CD137-dependent because they did not occur in severe combined immunodeficient, nude, RAG-/- (or rat IgG-deficient), or CD137-/- mice. CD8+ T cells, TNF- $\gamma$, type I IFNs, and IFN- $\gamma$ were essential for the induction of various aspects of pathology. These findings suggest that anti-CD137-induced activation leads to the production of proinflammatory cytokines, and they in turn, induce many, if not all, of the observed abnormalities found in antiCD137-treated mice. ${ }^{40}$ These outcomes have been attributed to enhanced $\mathrm{CD} 8+\mathrm{T}$ cell survival, induction or suppression of CD4+ T cell help, CD8+ regulatory T cells, T-helper type 1 cytokine production, enhanced CD8+ T cell and NK cell function, or regulation of antigen priming by dendritic cells. ${ }^{41}$

While studies in mice have demonstrated most of the mechanisms of anti-CD137 monoclonal antibody activity in vivo, those in monkeys have been important to test their tolerability. BMS-663513 was studied in cynomolgus monkeys that were immunized by intramuscular injections of both prostate-specific antigen (PSA) and simian immunodeficiency virus gag deoxyribonucleic acid (DNA) constructs, followed by BMS-663513. Enzyme-linked immunospot analyses of IFN- $\gamma$ production by the monkey PBMCs showed a consistent immune response, with an increased number of antigen-specific IFN- $\gamma$-secreting cells when BMS-663513 was added to the vaccine. BMS-663513 increased, by 1.7fold, the quantity of IFN- $\gamma$ released, suggesting a possible modulation by anti-CD137 monoclonal antibody, augmenting the effectiveness of DNA vaccines. ${ }^{35}$

\section{Clinical studies with BMS-6635 I3: an immune modulator of anti- CDI37 antibody for tumor therapy}

The clinical studies using BMS-663513 as an anticancer agent are summarized in Table $2 .^{42}$

BMS-663513 is a fully humanized monoclonal antibody agonist of CD137. Stimulation of CD137 enhances the immune response, specifically, an antitumor immune response, by a variety of mechanisms. ${ }^{43}$

Phase I and II data presented by Sznol et al focused initially only on melanoma patients (23 patients in Phase I) but expanded to add renal cell carcinoma and ovarian cancer patients (30 enrolled per tumor site in Phase II). ${ }^{44}$

The NCT00309023 study was an open-label, ascending, multidose Phase I-II study conducted in subjects with locally advanced or metastatic solid tumors. ${ }^{42}$ In the dose-escalation phase of the study, subjects were sequentially assigned to one of six dose cohorts $(0.3,1,3,6,10$, or $15 \mathrm{mg} / \mathrm{kg})$ to receive BMS-663513 as a 60-minute intravenous (IV) infusion once every 3 weeks. In the dose-expansion portion of the study, only subjects with melanoma, renal cell carcinoma, or ovarian carcinoma were eligible. Patients stratified by tumor types were randomized to receive one of three doses $(1,3$, or $10 \mathrm{mg} / \mathrm{kg})$ of BMS-663513. Fifty-four melanoma patients were treated. The reported toxicity was manageable,

Table 2 The clinical studies using BMS-6635/3 as an anticancer agent

\begin{tabular}{|c|c|c|c|c|}
\hline Status & Study & NCT identifier & Phase & Condition \\
\hline Terminated & $\begin{array}{l}\text { A Study of BMS- } 6635 \text { I } 3 \text { Administered in Combination } \\
\text { with Chemotherapy to Subjects with Advanced Solid } \\
\text { Malignancies }\end{array}$ & NCT0035I32548 & Phase I & Advanced solid malignancies \\
\hline Terminated & $\begin{array}{l}\text { A Study of BMS-6635I } 3 \text { in Combination with } \\
\text { Chemoradiation in Subjects with Non Small Cell Lung } \\
\text { Carcinoma (NSCLC) }\end{array}$ & NCT0046III I $0^{49}$ & Phase I & $\begin{array}{l}\text { Non-small-cell lung cancer } \\
\text { (NSCLC) }\end{array}$ \\
\hline Terminated & $\begin{array}{l}\text { Study of BMS- } 663513 \text { in Patients with Advanced } \\
\text { Cancer }\end{array}$ & NCT0030902342 & $\begin{array}{l}\text { Phase I/ } \\
\text { Phase II }\end{array}$ & Solid tumors \\
\hline Withdrawn & $\begin{array}{l}\text { Combination of Anti-CDI } 37 \text { and Ipilimumab in Patients } \\
\text { with Melanoma }\end{array}$ & NCT00803374 & Phase I & Melanoma \\
\hline Completed & Phase II, 2nd Line Melanoma - RAND Monotherapy & NCT006I $2664^{45}$ & Phase II & Melanoma \\
\hline Recruiting & $\begin{array}{l}\text { Safety, Tolerability, Pharmacokinetics, and } \\
\text { Immunoregulatory Study of Urelumab (BMS-6635I3) } \\
\text { in Subjects with Advanced and/or Metastatic Solid } \\
\text { Tumors and Relapsed/Refractory B-cell Non-Hodgkin's } \\
\text { Lymphoma }\end{array}$ & NCT0I47I $210^{46}$ & Phase I & $\begin{array}{l}\text { Cancer - solid tumors } \\
\text { and B-cell non-Hodgkin's } \\
\text { lymphoma }\end{array}$ \\
\hline Recruiting & $\begin{array}{l}\text { Combination Study of Urelumab and Rituximab in } \\
\text { Patients with B-cell Non-Hodgkin's Lymphoma or CLL }\end{array}$ & NCT0I77563| 47 & Phase I & B-cell malignancies \\
\hline
\end{tabular}

Note: Adapted from Seminars in Oncology, 37/5, Ascierto PA, Simeone E, Sznol M, Fu YX, Melero I, Clinical experiences with anti-CDI37 and anti-PD-I therapeutic antibodies, 508-516, Copyright 2010, with permission from Elsevier. ${ }^{14}$

Abbreviations: CLL, chronic lymphocytic leukemia; RAND, Research ANd Development. 
with fatigue, transaminitis, neutropenia, rash, and diarrhea as the most common adverse events. For 106 of the total 115 patients enrolled, the most frequent grade $\geq 2$ laboratory abnormalities were increases in alanine aminotransferase (ALT) (15\%) and aspartate transaminase (AST) (12\%), leukopenia $(8 \%)$, neutropenia $(6 \%)$, thrombocytopenia (4\%), and hyperbilirubinemia $(<1 \%)$. This study showed clinical activity that justified further development of BMS663513 , both as a single agent and in combination, across a wide range of doses. Clinical activity represented by partial remissions and sustained stable diseases was observed in the 1,3 , and $10 \mathrm{mg} / \mathrm{kg}$ groups. More toxicity was shown at higher doses $(>6 \mathrm{mg} / \mathrm{kg})$. Results of biomarkers studies (activated T cell markers, ribonucleic acid [RNA] expression, and serum biomolecules) indicated that BMS-663513 elicited biologic activity with doses as low as $0.3 \mathrm{mg} / \mathrm{kg}$. NCT00309023 $3^{42}$ has provided the rationale for developing a Phase II randomized study in previously treated melanoma patients with stage IV disease (NCT00612664). ${ }^{45}$ The main purpose of this study is to estimate the proportion of patients with melanoma who are progression-free, (that is, the cancer has not become substantially worse), when treated with antiCD137 (BMS-663513) at $0.1 \mathrm{mg} / \mathrm{kg}, 1 \mathrm{mg} / \mathrm{kg}$, or $5 \mathrm{mg} / \mathrm{kg}$ every 3 weeks or $1 \mathrm{mg} / \mathrm{kg}$ every 6 weeks. This clinical trial is being conducted on 158 patients enrolled from 32 study locations. Additionally, two Phase I clinical trials of BMS663513 (NCT01471210 $0^{46}$ and NCT0177563147) are both currently in the recruitment stage.

\section{Conclusion}

In conclusion, solid tumors, including melanoma, renal carcinoma, and ovarian cancer, remain deadly diseases, and new therapeutic approaches are needed. Targeted tumor immunotherapy is an exciting field, although in many aspects, it will challenge our common wisdom regarding drug development in oncology. The cellular immune response is tightly modulated to control the ability to generate cytotoxicity and inflammation, and we are just starting to learn how to unleash or stimulate it within a reasonably safe therapeutic window. The understanding of its control offers an opportunity to regulate its intensity. CD137 stands out as one of the promising targets for immune costimulatory monoclonal antibodies, in light of its clinical and preclinical records. BMS-663513, a humanized anti-CD137 monoclonal antibody, is currently in clinical trials in patients with both solid tumors and B-cell malignancies and so far, seems to have a favorable toxicity profile. Preclinical evidence for synergy with conventional and other immunotherapies are abundant, and stepwise combinations should lead the way toward much needed efficacy at the bedside. Novel immunotherapeutic strategies and safe dosing, with tolerable liver toxicity, may hold the key to future successes in the path forward.

\section{Disclosure}

The authors report no conflicts of interest in this work.

\section{References}

1. Rainmakers MI, Rozati S, Goldinger SM, Widmer DS, Dummer R, Levesque MP. Melanoma immunotherapy: historical precedents, recent successes and future prospects. Immunotherapy. 2013;5(2):169-182.

2. Lee C, Collichio F, Ollila D, Moschos S. Historical review of melanoma treatment and outcomes. Clin Dermatol. 2013;31(2):141-147.

3. Lee AF, Sieling PA, Lee DJ. Immune correlates of melanoma survival in adoptive cell therapy. Oncoimmunology. 2013;2(2):e22889.

4. Wolchok J. How recent advances in immunotherapy are changing the standard of care for patients with metastatic melanoma. Ann Oncol. 2012;23 Suppl 8:viii15-viii21.

5. Maio M. Melanoma as a model tumour for immuno-oncology. Ann Oncol. 2012;23 Suppl 8:viii10-viii14.

6. Kushnir I, Merimsky O. The evolution in melanoma treatment as a reflection of precision-oriented medicine. Oncol Lett. 2013;5(2):424-426.

7. Ribas A. Update on immunotherapy for melanoma. J Natl Compr Canc Netw. 2006;4(7):687-694.

8. Boon T, Coulie PG, Van den Eynde BJ, van der Bruggen P. Human T cell responses against melanoma. Annu Rev Immunol. 2006;24:175-208.

9. Stagg J, Johnstone RW, Smyth MJ. From cancer immunosurveillance to cancer immunotherapy. Immunol Rev. 2007;220:82-101.

10. Ballestrero A, Boy D, Moran E, Cirmena G, Brossart P, Nencioni A. Immunotherapy with dendritic cells for cancer. Adv Drug Deliv Rev. 2008;60(2):173-183.

11. Chaudhuri D, Suriano R, Mittelman A, Tiwari RK. Targeting the immune system in cancer. Curr Pharm Biotechnol. 2009;10(2):166-184.

12. Nishikawa H, Sakaguchi S. Regulatory T cells in tumor immunity. Int J Cancer. 2010;127(4):759-767.

13. Hersey P. Immunotherapy of melanoma. Asia Pac J Clin Oncol. 2010;6 Suppl 1:S2-S8.

14. Ascierto PA, Simeone E, Sznol M, Fu YX, Melero I. Clinical experiences with anti-CD137 and anti-PD1 therapeutic antibodies. Semin Oncol. 2010;37(5):508-516.

15. Cheuk AT, Mufti GJ, Guinn BA. Role of 4-1BB:4-1BB ligand in cancer immunotherapy. Cancer Gene Ther. 2004;11(3):215-226.

16. Nam KO, Kang WJ, Kwon BS, Kim SJ, Lee HW. The therapeutic potential of 4-1BB (CD137) in cancer. Curr Cancer Drug Targets. 2005;5(5):357-363.

17. Sun Y, Chen JH, Fu Y. Immunotherapy with agonistic anti-CD137: two sides of a coin. Cell Mol Immunol. 2004;1(1):31-36.

18. Lynch DH. The promise of 4-1BB (CD137)-mediated immunomodulation and the immunotherapy of cancer. Immunol Rev. 2008;222: 277-286.

19. Lee SW, Croft M. 4-1BB as a therapeutic target for human disease. Adv Exp Med Biol. 2009;647:120-129.

20. Vinay DS, Kwon BS. Immunotherapy of cancer with 4-1BB. Mol Cancer Ther. 2012;11(5):1062-1070.

21. Melero I, Shuford WW, Newby SA, et al. Monoclonal antibodies against the 4-1BB T-cell activation molecule eradicate established tumors. Nat Med. 1997;3(6):682-685.

22. Mittler RS, Bailey TS, Klussman K, Trailsmith MD, Hoffmann MK. Anti-4-1BB monoclonal antibodies abrogate T cell-dependent humoral immune responses in vivo through the induction of helper T cell anergy. J Exp Med. 1999;190(10):1535-1540. 
23. Sabel MS, Conway TF, Chen FA, Bankert RB. Monoclonal antibodies directed against the T-cell activation molecule CD137 (interleukin-A or 4-1BB) block human lymphocyte-mediated suppression of tumor xenografts in severe combined immunodeficient mice. J Immunother. 2000;23(3):362-368.

24. Kim JA, Averbook BJ, Chambers K, et al. Divergent effects of 4-1BB antibodies on antitumor immunity and on tumor-reactive T-cell generation. Cancer Res. 2001;61(5):2031-2037.

25. Wilcox RA, Flies DB, Zhu G, et al. Provision of antigen and CD137 signaling breaks immunological ignorance, promoting regression of poorly immunogenic tumors. J Clin Invest. 2002;109(5):651-659.

26. May KF, Chen L, Zheng P, Liu Y. Anti-4-1BB monoclonal antibody enhances rejection of large tumor burden by promoting survival but not clonal expansion of tumor-specific CD8+ T cells. Cancer Res 2002;62(12):3459-3465.

27. Miller RE, Jones J, Le T, et al. 4-1BB-specific monoclonal antibody promotes the generation of tumor-specific immune responses by direct activation of CD8 T cells in a CD40-dependent manner. J Immunol. 2002;169(4):1792-1800.

28. Ju SA, Cheon SH, Park SM, et al. Eradication of established renal cell carcinoma by a combination of 5-fluorouracil and anti-4-1BB monoclonal antibody in mice. Int J Cancer. 2008;122(12):2784-2790.

29. Palazón A, Teijeira A, Martínez-Forero I, et al. Agonist antiCD137 mAb act on tumor endothelial cells to enhance recruitment of activated T lymphocytes. Cancer Res. 2011;71(3):801-811.

30. June $\mathrm{CH}$. Adoptive $\mathrm{T}$ cell therapy for cancer in the clinic. J Clin Invest. 2007;117(6):1466-1476.

31. Hernandez-Chacon JA, Li Y, Wu RC, et al. Costimulation through the CD137/4-1BB pathway protects human melanoma tumor-infiltrating lymphocytes from activation-induced cell death and enhances antitumor effector function. J Immunother. 2011;34(3):236-250.

32. Zhu BQ, Ju SW, Shu YQ. CD137 enhances cytotoxicity of CD3(+) CD56(+) cells and their capacities to induce CD4(+) Th1 responses. Biomed Pharmacother. 2009;63(7):509-516.

33. Lu PH, Negrin RS. A novel population of expanded human CD3+CD56+ cells derived from $T$ cells with potent in vivo antitumor activity in mice with severe combined immunodeficiency. J Immunol. 1994;153(4): 1687-1696.

34. Verneris MR, Arshi A, Edinger M, et al. Low levels of Her2/neu expressed by Ewing's family tumor cell lines can redirect cytokineinduced killer cells. Clin Cancer Res. 2005;11(12):4561-4570.

35. Melero I, Hervas-Stubbs S, Glennie M, Pardoll DM, Chen L. Immunostimulatory monoclonal antibodies for cancer therapy. Nat Rev Cancer. 2007;7(2):95-106.

36. Ito F, Li Q, Shreiner AB, et al. Anti-CD137 monoclonal antibody administration augments the antitumor efficacy of dendritic cell-based vaccines. Cancer Res. 2004;64(22):8411-8419.

37. Uno T, Takeda K, Kojima Y, et al. Eradication of established tumors in mice by a combination antibody-based therapy. Nat Med. 2006;12(6):693-698.
38. Kocak E, Lute $\mathrm{K}$, Chang $\mathrm{X}$, et al. Combination therapy with anti-CTL antigen-4 and anti-4-1BB antibodies enhances cancer immunity and reduces autoimmunity. Cancer Res. 2006;66(14):7276-7284.

39. Kim YH, Choi BK, Kim KH, Kang SW, Kwon BS. Combination therapy with cisplatin and anti-4-1BB: synergistic anticancer effects and amelioration of cisplatin-induced nephrotoxicity. Cancer Res. 2008;68(18):7264-7269.

40. Takahashi C, Mittler RS, Vella AT. Cutting edge: 4-1BB is a bona fide CD8 T cell survival signal. J Immunol. 1999;162(9):5037-5040.

41. Wilcox RA, Tamada K, Flies DB, et al. Ligation of CD137 receptor prevents and reverses established anergy of CD8+ cytolytic T lymphocytes in vivo. Blood. 2004;103(1):177-184.

42. Bristol-Myers Squibb. Study of BMS-663513 in Patients With Advanced Cancer. Available from: http://clinicaltrials.gov/ct2/show/ NCT00309023.NLM identifier: NCT00309023. Accessed July 20, 2013.

43. Melero I, Murillo O, Dubrot J, Hervás-Stubbs S, Perez-Gracia JL. Multi-layered action mechanisms of CD137 (4-1BB)-targeted immunotherapies. Trends Pharmacol Sci. 2008;29(8):383-390.

44. Sznol M, Hodi FS, Margolin K, et al. Phase I study of BMS-663513, a fully human anti-CD137 agonist monoclonal antibody, in patients (pts) with advanced cancer (CA) [Abstract]. J Clin Oncol (Meeting Abstracts). 2008;26(Suppl 15):3007.

45. Bristol-Myers Squibb.Phase II, 2nd Line Melanoma - RAND Monotherapy. Available from: http://clinicaltrials.gov/show/NCT00612664 NLM identifier: NCT00612664. Accessed July 30, 2013.

46. Bristol-Myers Squibb. Safety, Tolerability, Pharmacokinetics, and Immunoregulatory Study of Urelumab (BMS-663513) in Subjects With Advanced and/or Metastatic Solid Tumors and Relapsed/Refractory B-cell Non-Hodgkin's Lymphoma. Available from: http:/clinicaltrials. gov/show/NCT01471210. NLM identifier: NCT01471210. Accessed July 20, 2013.

47. Bristol-Myers Squibb. Combination Study of Urelumab and Rituximab in Patients With B-cell Non-Hodgkins Lymphoma or CLL. Available from: http:/clinicaltrials.gov/show/NCT01775631. NLM identifier: NCT01775631. Accessed July 20, 2013.

48. Bristol-Myers Squibb. A Study of BMS-663513 Administered in Combination With Chemotherapy to Subjects With Advanced Solid Malignancies. Available from: http://clinicaltrials.gov/show/NCT00351325 NLM identifier: NCT00351325. Accessed July 20, 2013.

49. Bristol-Myers Squibb. A Study of BMS-663513 in Combination With Chemoradiation in Subjects With Non Small Cell Lung Carcinoma (NSCLC). Available from: http://clinicaltrials.gov/ct2/show/ NCT00461110. NLM identifier: NCT00461110. Accessed July 20, 2013.

50. Bristol-Myers Squibb. Combination of Anti-CD137 \& Ipilimumab in Patients With Melanoma. Available from: http://clinicaltrials.gov/ct2/ show/NCT00803374. NLM identifier: NCT00803374. Accessed July $20,2013$.
Clinical Pharmacology: Advances and Applications

\section{Publish your work in this journal}

Clinical Pharmacology: Advances and Applications is an international, peer-reviewed, open access journal publishing original research, reports, reviews and commentaries on all areas of drug experience in humans. The manuscript management system is completely online and includes a very quick and fair peer-review system, which is all easy to use.

\section{Dovepress}

Visit http://www.dovepress.com/testimonials.php to read real quotes from published authors. 